\title{
A Neutral Heteroatomic Zintl Cluster for the Catalytic Hydrogenation of Cyclic Alkenes
}

\author{
Oliver P. E. Townrow, Cheuk Chung, Stuart A. Macgregor, Andrew S. Weller,* and Jose M. Goicoechea*
}

Cite This: J. Am. Chem. Soc. 2020, 142, 18330-18335

Read Online

ABSTRACT: We report on the synthesis of an alkane-soluble Zintl cluster, $\left[\eta^{4}-\mathrm{Ge}_{9}(\mathrm{Hyp})_{3}\right] \mathrm{Rh}(\mathrm{COD})$, that can catalytically hydrogenate cyclic alkenes such as 1,5-cyclooctadiene and cis-cyclooctene. This is the first example of a well-defined Zintl-clusterbased homogeneous catalyst.

$\mathrm{L}$ iquid metal alloys have found applications in catalysis, flexible electronics, and the synthesis of new materials. ${ }^{1}$ As catalysts they have proved to be active in processes such as alkane dehydrogenation ${ }^{2-5}$ and the electrochemical reduction of carbon dioxide. ${ }^{6}$ Typically, such catalysts employ transition metals in conjunction with low-melting-point main-group elements (e.g., gallium, indium, tin, lead, or bismuth), although it is worth noting that in the catalytic dehydrogenation of methane, for example, the main-group-element "solvents" have been shown to be moderately active in the absence of transition metals. ${ }^{2}$ Despite these applications, the nature of the catalytically active species present in such melts remains elusive, and in situ monitoring represents a significant challenge.

With this in mind, we set out to develop well-defined molecular models of transition-metal/main-group-element alloys (TMMGAs) in an effort to model structure and probe reaction mechanisms that occur for molten alloys. For this purpose, we targeted late transition metals supported on maingroup-element clusters, given that cluster-like moieties are postulated to exist in liquid metal alloys. ${ }^{1}$ As a support, we chose $\left[\mathrm{Ge}_{9}(\mathrm{Hyp})_{3}\right]^{-}\left(\mathrm{Hyp}=\mathrm{Si}\left(\mathrm{SiMe}_{3}\right)_{3}\right){ }^{7,8}$ This cluster, and related species with heteroleptic exo substituents, ${ }^{9}$ have been employed as ligands in the coordination chemistry of transition metals. ${ }^{10-12}$ Herein we demonstrate that $\left[\mathrm{Ge}_{9} \mathrm{Hyp}_{3}\right]^{-}$can act as a suitable platform for the synthesis of hydrocarbon-soluble TMMGAs and that these species are catalysts for the hydrogenation of 1,5-cyclooctadiene (COD) (and cis-cyclooctene $(\mathrm{COE}))$. To the best of our knowledge, this is the first instance of the use of Zintl clusters in homogeneous catalysis. $^{13,14}$

$\mathrm{K}\left[\mathrm{Ge}_{9}(\mathrm{Hyp})_{3}\right]$ was reacted with 0.5 equiv of $[\mathrm{Rh}(\mathrm{COD})$ $\mathrm{Cl}]_{2}$ to afford $\left[\eta^{4}-\mathrm{Ge}_{9}(\mathrm{Hyp})_{3}\right] \mathrm{Rh}(\mathrm{COD})(\mathbf{1})$ (Scheme 1). The reaction gives rise to a species that exhibits two hypersilyl singlet resonances in the ${ }^{1} \mathrm{H}$ NMR spectrum at 0.29 and 0.57 ppm (in a 2:1 ratio) accompanied by resonances for the coordinated COD ligand at 1.93, 2.31, and $5.48 \mathrm{ppm}$, each with a $4 \mathrm{H}$ relative integral. ${ }^{13} \mathrm{C}\left\{{ }^{1} \mathrm{H}\right\}$ and ${ }^{1} \mathrm{H} /{ }^{29} \mathrm{Si} \mathrm{HMBC}$ NMR spectra support the existence of two inequivalent hypersilyl substituents. Close inspection of the NMR spectra reveals a minor component (approximately 10\%) that exhibits two
Scheme 1. Synthesis of 1

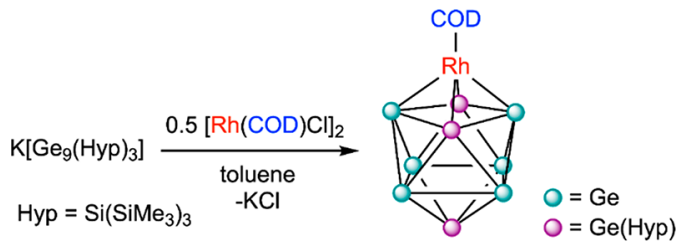

hypersilyl resonances in the ${ }^{1} \mathrm{H}$ NMR spectrum at 0.47 and $0.53 \mathrm{ppm}$ and resonances corresponding to a coordinated COD ligand at $2.06,2.41$, and $4.31 \mathrm{ppm}$. As the compositional purity of 1 was determined by combustion analysis and dissolution of crystals of this compound (which showed the presence of only one isomer by single-crystal X-ray diffraction) gave rise to the same ratio of species at room temperature, we suggest that this minor component corresponds to an isomer of undetermined connectivity, possibly $\left[\eta^{5}-\mathrm{Ge}_{9}(\mathrm{Hyp})_{3}\right] \mathrm{Rh}$ (COD) (cf. compound 2 below). There is no exchange between the two isomers on the NMR time scale, as probed by variable-temperature NMR studies (193-333 K), but it does appear that the minor isomer is fluxional in this temperature range (see Figures S8 and S9).

Dark-red crystals of $\mathbf{1}$ suitable for single-crystal X-ray diffraction were obtained in $88 \%$ yield from an $n$-hexane solution stored at $-80{ }^{\circ} \mathrm{C}$ (Figure 1). The asymmetric unit contains two crystallographically inequivalent clusters with similar bond metrics (see the Supporting Information). Only one of these is shown. The cluster adopts a $C_{2 v}$-symmetric bicapped square-antiprismatic geometry in which the Rh(COD) fragment occupies one of the capping positions. From an electron-counting perspective, this is a closo-deltahedral species with 22 electrons available for cluster bonding. The

Received: September 16, 2020

Published: October 14, 2020 


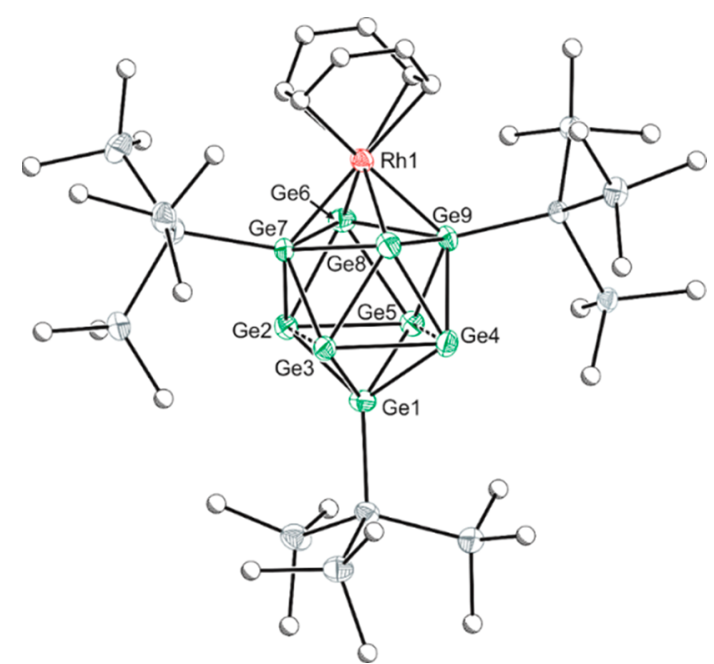

Figure 1. Molecular structure of 1. Anisotropic displacement ellipsoids are set at 50\% probability. Hydrogen atoms have been omitted for clarity. Carbon atoms are pictured as spheres of arbitrary radius.

$\left[\mathrm{Ge}_{9}(\mathrm{Hyp})_{3}\right]^{-}$cluster coordinates to the rhodium(I) atom in an $\eta^{4}$ mode. While this binding mode has not been previously observed for such silylated clusters, ${ }^{10-12}$ it is well-documented for substituent-free clusters such as $\left[\mathrm{E}_{9} \mathrm{M}(\mathrm{CO})_{3}\right]^{4-}(\mathrm{E}=\mathrm{Sn}$, $\mathrm{Pb} ; \mathrm{M}=\mathrm{Cr}, \mathrm{Mo}, \mathrm{W})$ and $\left[\mathrm{E}_{9} \operatorname{Ir}(\mathrm{COD})\right]^{3-}(\mathrm{E}=\mathrm{Sn}, \mathrm{Pb}) .{ }^{15,16}$

The $\mathrm{Rh}-\mathrm{Ge}$ bond distances in 1 range from 2.496(2) to 2.581(2) $\AA$, while the distances to the coordinated COD ligand vary between $2.168(11)$ and $2.218(12) \AA$. These latter values are similar to those in related complexes featuring a $\mathrm{Rh}(\mathrm{COD})$ moiety (mean $\mathrm{Rh}-\mathrm{C}$ distance $2.16(5) \AA)^{17}$, such as [(Mes)$\mathrm{Rh}(\mathrm{COD})]\left[\mathrm{SbF}_{6}\right]$ (Mes = 1,3,5-trimethylbenzene; mean $\mathrm{Rh}-$ C distance $2.148 \AA)^{18}$

Reaction of 1 with 1 equiv of 1,2-bis(diphenylphosphino)ethane (dppe) results in displacement of the coordinated COD ligand to afford $\left[\eta^{5}-\mathrm{Ge}_{9}(\mathrm{Hyp})_{3}\right] \mathrm{Rh}(\mathrm{dppe})$ (2) (Scheme 2). In

Scheme 2. Synthesis of 2

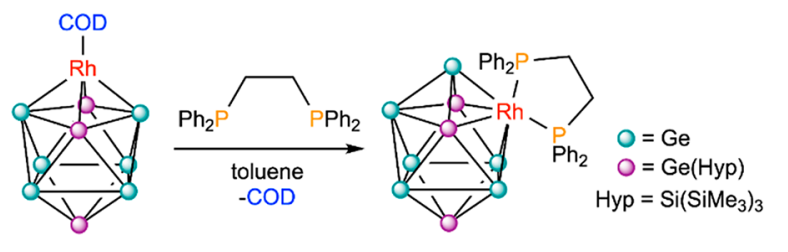

contrast to $\mathbf{1}$, the ${ }^{1} \mathrm{H}$ and ${ }^{13} \mathrm{C}\left\{{ }^{1} \mathrm{H}\right\}$ NMR spectra of this compound in $\mathrm{C}_{6} \mathrm{D}_{6}$ reveal the presence of a single resonance corresponding to the hypersilyl groups $\left({ }^{1} \mathrm{H}, 0.46 \mathrm{ppm} ;{ }^{13} \mathrm{C}\right.$ $\left.\left\{{ }^{1} \mathrm{H}\right\}, 3.96 \mathrm{ppm}\right)$ in addition to resonances corresponding to the dppe ligand. This observation suggests a change in the coordination mode of the cluster with the rhodium metal center, which was confirmed by the presence of only two crosspeaks in the ${ }^{1} \mathrm{H} /{ }^{29} \mathrm{Si} \mathrm{HMBC}$ NMR spectrum at -84.4 and $9.8 \mathrm{ppm}$. A single doublet resonance was observed in the ${ }^{31} \mathrm{P}\left\{{ }^{1} \mathrm{H}\right\}$ NMR spectrum at $43.9 \mathrm{ppm}[J(\mathrm{Rh}-\mathrm{P})=160 \mathrm{~Hz}]$. This is comparable to those of other closo clusters such as the metallacarborane 2-Ph-closo-1,2,3,4-Rh(dppe) $\mathrm{C}_{3} \mathrm{~B}_{7} \mathrm{H}_{9}\left(\delta\left({ }^{31} \mathrm{P}\right)\right.$ $57.5 \mathrm{ppm}, J(\mathrm{Rh}-\mathrm{P})=165 \mathrm{~Hz}) .{ }^{19}$

Crystals of 2 were grown from concentrated $n$-pentane solutions at $-40{ }^{\circ} \mathrm{C}$. The single-crystal X-ray structure (Figure 2) confirms that there is a change in the binding mode of the

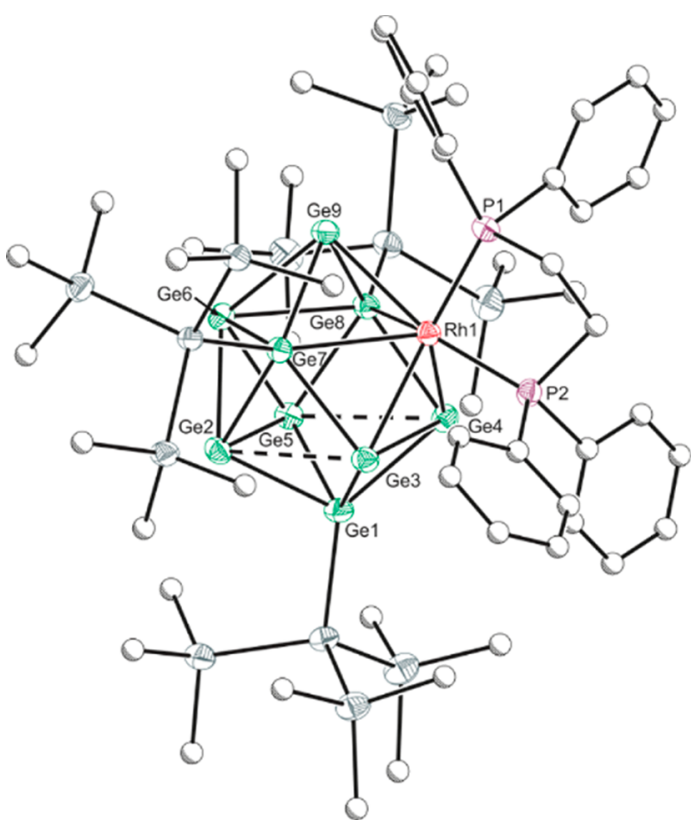

Figure 2. Molecular structure of 2. Anisotropic displacement ellipsoids are set at $50 \%$ probability. Hydrogen atoms have been omitted for clarity. Carbon atoms are pictured as spheres of arbitrary radius.

cluster. This presents inequivalent phosphine and hypersilyl environments, in contrast to the solution NMR data. This points to a dynamic process on the NMR time scale in solution that provides time-averaged $C_{3 v}$ symmetry (see Figure S15). An alternative dissociative process that generates a chargeseparated ion pair, $\left[\mathrm{Rh}(\mathrm{dppe})\left(\eta^{6}-\mathrm{C}_{6} \mathrm{D}_{6}\right)\right]\left[\mathrm{Ge}_{9}(\mathrm{Hyp})_{3}\right]$, is discounted because no evidence for $\left[\mathrm{Rh}(\text { dppe })\left(\eta^{6}-\mathrm{C}_{6} \mathrm{D}_{6}\right)\right]^{+}$ was observed in the NMR spectra. ${ }^{20}$ Variable-temperature NMR experiments (in $\mathrm{C}_{7} \mathrm{D}_{8}$ to $193 \mathrm{~K}$; Figure S14) did not result in any significant change. Related $\left[\eta^{5}-\mathrm{Ge}_{9}(\mathrm{Hyp})_{3}\right]$ functionalized clusters are also fluxional and exhibit a single resonance for the hypersilyl substituents in their ${ }^{1} \mathrm{H}$ NMR spectra. $^{11 \mathrm{~b}, \mathrm{~d}}$

While electronically similar to $\mathbf{1}$, the $\mathrm{Rh}$ (dppe) fragment in $\mathbf{2}$ now occupies one of the five-connected vertices of the bicapped square-antiprismatic structure. The $\mathrm{Rh}-\mathrm{Ge}$ distances are in the range of $2.561(1)$ and $2.837(1) \AA$, which are longer than comparable distances in 1 (cf. 2.496(2)-2.581(2) $\AA$ ). This may be a result of the significant steric clash between the hypersilyl and phenyl groups. The Rh-P distances (2.286(1) and $2.356(1) \AA$ ) are as expected for related compounds featuring a $\mathrm{Rh}$ (dppe) fragment (mean $\mathrm{Rh}-\mathrm{P}$ distance $2.27(6)$ $\AA$ ), ${ }^{21}$ such the 2-Ph-closo-1,2,3,4-Rh(dppe) $\mathrm{C}_{3} \mathrm{~B}_{7} \mathrm{H}_{9}$ cluster, which has $\mathrm{Rh}-\mathrm{P}$ distances of 2.232(1) and 2.285(1) $\AA^{19}$

Compound 1 has a surface of accessible lone pairs from the unsubstituted germanium vertices. Reaction with 2 equiv of $\mathrm{Ni}(\mathrm{COD})_{2}$ yields a species that exhibits two singlet resonances in its ${ }^{1} \mathrm{H}$ NMR spectrum, suggesting two inequivalent hypersilyl groups, that are accompanied by two sets of resonances for coordinated COD ligands in a 2:1 ratio (Scheme 3). Crystallization of this compound from $n$-pentane and a resulting structural analysis revealed a cluster with two $\mathrm{Ni}(\mathrm{COD})$ fragments that associate with the triangular faces of the $\left[\eta^{4}-\mathrm{Ge}_{9}(\mathrm{Hyp})_{3}\right] \mathrm{Rh}(\mathrm{COD})$ core (see Figure S21). Conversion of 1 to 3 is quantitative, and both of the isomeric forms 
Scheme 3. Synthesis of 3
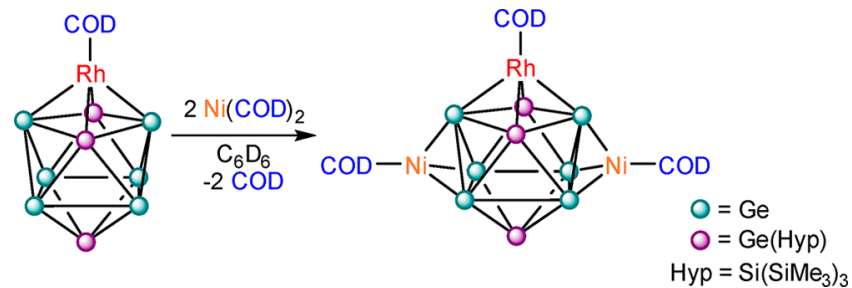

of 1 observed in solution cleanly convert to a single species. This is also the case with the synthesis of 2 .

Compound $\mathbf{1}$ was evaluated as a catalyst for the hydrogenation of COD or COE to give cyclooctane (COA) (eq 1):

$$
\mathrm{COD} \text { or } \mathrm{COE} \underset{+\mathrm{H}_{2}}{\stackrel{\mathbf{1}(2 \mathrm{~mol} \%)}{\longrightarrow}} \mathrm{COA}
$$

While this is a well-known reaction for homogeneous $\mathrm{Rh}$ precatalysts, ${ }^{22}$ as far as we are aware, this is the first example in which a Zintl cluster acts as a homogeneous catalyst. ${ }^{23,24}$

Initial in situ screening using NMR spectroscopy ( $2 \mathrm{~mol} \%$ 1, $\sim 4$ atm $\mathrm{H}_{2}$, [alkene $]_{0}=0.31 \mathrm{M}, \mathrm{C}_{6} \mathrm{D}_{6}, 298 \mathrm{~K}$ ) showed that COD was hydrogenated considerably more slowly than $\mathrm{COE}$ $(8.5 \mathrm{~h}$ vs $15 \mathrm{~min})$. Aware of the problems with mass transport effects in NMR-scale reactions, ${ }^{25}$ we collected kinetics data using a system open to flowing $\mathrm{H}_{2}$ (1 atm) and stirred, with individual time/concentration points coming from separate quenched experiments as measured using ${ }^{1} \mathrm{H}$ NMR spectroscopy. Under these conditions, hydrogenation was much slower (days for COD hydrogenation), suggesting a positive order in $\mathrm{H}_{2}$. The temporal profiles for the two substrates were also very different from one another (Scheme $4 \mathrm{~A}$ ). While monitoring of

Scheme 4. (A) Kinetic Data $(O)$ and Simulated Data for Hydrogenation of (top) COD and (bottom) COE; (B) Proposed Mechanism

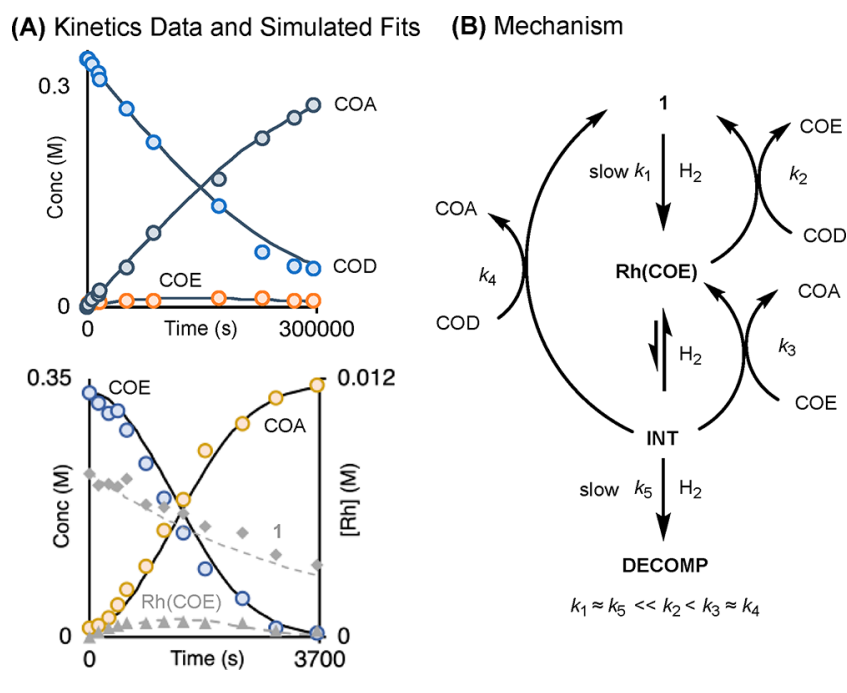

the COD hydrogenation showed steadily decelerating consumption of substrate and production of COA, for COE a more complex sinusoidal profile was observed, with induction, acceleration, and then deceleration phases. The generation of a colloidal catalyst from $\mathbf{1}$ in COD hydrogenation was discounted, as addition of $\mathrm{Hg}$ during productive catalysis did not affect the observed rate. ${ }^{26}$ Complex 1 was observed as the principal resting state using both substrates, but its concentration decreased significantly over time. For COE hydrogenation, an additional minor species that shows $\mathrm{Rh}$ (olefin) resonances is observed to grow in and then disappear. Addition of $\mathrm{H}_{2}$ to complex 1 in the absence of substrate resulted in the formation of an unidentified precipitate over $8 \mathrm{~h}$, while recharging post-catalysis resulted in no turnover. Both observations suggest a slow $\mathrm{H}_{2}$-promoted decomposition. To resolve this rather complex set of observations, we modeled the processes occurring using COPASI. $^{27}$

Scheme 4A shows the resulting fits to the kinetics data, which arise from a model that operates for either COD or COE starting points and was iterated on the observed concentrations of substrates, intermediates, products, organometallic speciation, and slow decomposition with a constant excess of $\mathrm{H}_{2}$. The COE hydrogenation cycle was first modeled, and specific rate constants were fixed, after which the model was used for the COD analysis. The resulting simulation recreates the multiple temporal profiles satisfactorily, giving confidence that it captures the essential elements of the catalytic manifold. Briefly described, slow hydrogenation of $\mathbf{1}$ results in an intermediate species, $\mathrm{Rh}(\mathrm{COE})$, which we propose is the species observed in low concentrations during COE hydrogenation. $\mathbf{R h}(\mathrm{COE})$ then undergoes either further (endergonic) reaction with $\mathrm{H}_{2}$ to eventually form INT, or simple substitution by COD to return 1 and give free $\mathrm{COE}$ (observed). Under COD hydrogenation conditions, reaction of INT with COD again returns $\mathbf{1}$. With $\mathrm{COE}, \mathbf{R h}(\mathrm{COE})$ is formed. Both cycles produce COA. While the observed induction period in COE hydrogenation is explained by slow $\mathbf{R h}(\mathrm{COE})$ buildup, for both substrates compound $\mathbf{1}$ is the principal resting state. The deceleration at longer reaction times in both COE and COD hydrogenations and the reduction in [1] are captured by the inclusion of a slow decomposition process with $\mathrm{H}_{2}$ that reduces $[\mathrm{Rh}]_{\text {total }}$ as observed experimentally in the absence of COD. Complex 2 is not an active catalyst, consistent with the strongly bound dppe ligand, whereas the reaction with $\mathbf{3}$ is significantly slower than that with 1 , taking 1 week to effect only $50 \%$ conversion of COD (NMR tube, 4 atm $\mathrm{H}_{2}$ ). Interestingly, free $\mathrm{COE}$ is the major product at this point $(\mathrm{COE}: \mathrm{COA}=9: 1)$. Binding of the two $\mathrm{Ni}(\mathrm{COD})$ fragments to the core of 1 significantly alters the electronics of the cluster (as evidenced by pronounced changes to bond metric data-see Figure S21). We postulate that this has an effect on the strength of the $\mathrm{Rh}-\mathrm{COD}$ interaction, which in turn alters the kinetics of the reaction.

In order to probe the viability of the proposed mechanism, key reaction pathways were probed using density functional theory calculations (see Scheme 5 and Figures S30 and S31). Because of the 18-electron configuration of 1 , the most accessible pathway begins with an $\eta^{4}-\eta^{2}$ dissociation of the COD ligand, with a barrier of $+19.6 \mathrm{kcal} / \mathrm{mol}$. The resulting 16-electron $\mathrm{Rh}(\mathrm{I})$ intermediate then reversibly adds $\mathrm{H}_{2}$ to form a $\mathrm{Rh}(\mathrm{III})$ dihydride intermediate at $+16.8 \mathrm{kcal} / \mathrm{mol}$ relative to 1 . Migratory insertion then produces an agostically stabilized alkyl hydride that can rearrange via a non-agostic alkyl hydride intermediate, allowing reductive coupling to form $\mathbf{R h}(\mathbf{C O E})$ at $-1.9 \mathrm{kcal} / \mathrm{mol}$. The overall barrier for the formation of $\mathrm{Rh}(\mathrm{COE})$ from $\mathbf{1}$ is $+27.1 \mathrm{kcal} / \mathrm{mol}$ with a turnover-limiting step corresponding to the reductive coupling process. Displacement of COE by COD may occur at this point to reform 1, or $\mathbf{R h}(\mathrm{COE})$ may itself undergo hydrogenation. This second hydrogenation occurs by a similar 
Scheme 5. Condensed Reaction Mechanism for the Hydrogenation of COD with $1^{a}$

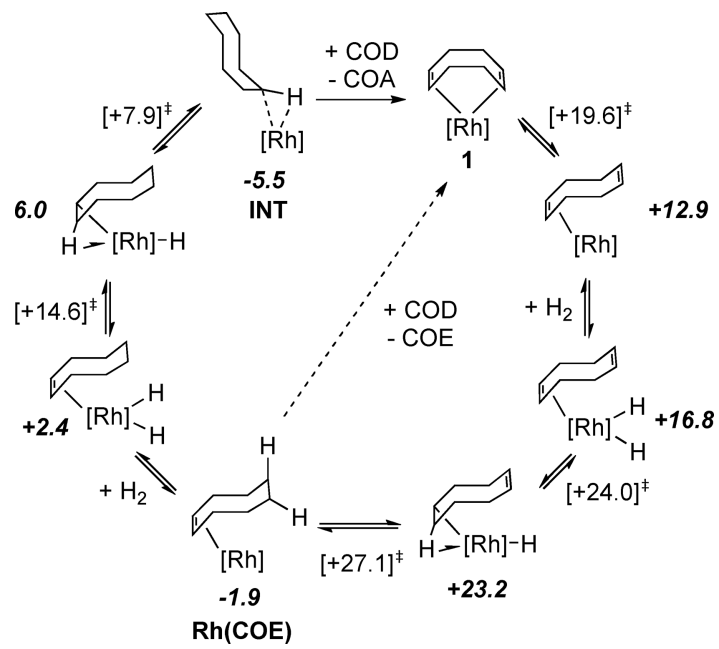

${ }^{a}[\mathrm{Rh}]=\left[\eta^{4}-\mathrm{Ge}_{9}(\mathrm{Hyp})_{3}\right] \mathrm{Rh}$. All energies are in $\mathrm{kcal} \mathrm{mol}^{-1}$ relative to 1.

pathway, albeit with a lower overall barrier of $+16.5 \mathrm{kcal} / \mathrm{mol}$ toward a final intermediate (INT) that is rapidly converted to $\mathbf{1}$ in the presence of COD. These relative barriers and energies of the intermediates account for the experimental observations of an induction period for COE hydrogenation, the faster hydrogenation of COE compared with COD, and the observed speciation during catalysis.

To conclude, we have shown that metal-functionalized Zintl clusters can be employed as homogeneous catalysts and act as molecular models for more complex catalysts such as TMMGAs that are challenging to study in situ. The welldefined structures of these clusters and the ease with which the cluster composition can be tuned may ultimately allow for the custom synthesis of heteroatomic compounds tailored for bespoke catalytic processes.

\section{ASSOCIATED CONTENT}

\section{SI Supporting Information}

The Supporting Information is available free of charge at https://pubs.acs.org/doi/10.1021/jacs.0c09742.

Experimental procedures, spectra, additional discussion, DFT methods, computed energies, and kinetic data (PDF)

Cartesian coordinates (XYZ)

Crystallographic data for $\mathbf{1}$ (CIF)

Crystallographic data for 2 (CIF)

Crystallographic data for 3 (CIF)

\section{AUTHOR INFORMATION}

\section{Corresponding Authors}

Andrew S. Weller - Department of Chemistry, University of York, York YO10 5DD, U.K.; 이이이.org/0000-0003-16468081; Email: andrew.weller@york.ac.uk

Jose M. Goicoechea - Department of Chemistry, University of Oxford, Oxford OX1 3TA, U.K.; $\odot$ orcid.org/0000-0002-

7311-1663; Email: jose.goicoechea@chem.ox.ac.uk

\section{Authors}

Oliver P. E. Townrow - Department of Chemistry, University of Oxford, Oxford OX1 3TA, U.K.; (1) orcid.org/0000-00019556-6450

Cheuk Chung - Department of Chemistry, University of Oxford, Oxford OX1 3TA, U.K.

Stuart A. Macgregor - Institute of Chemical Sciences, Heriot Watt University, Edinburgh EH14 4AS, U.K.; (1) orcid.org/ 0000-0003-3454-6776

Complete contact information is available at:

https://pubs.acs.org/10.1021/jacs.0c09742

\section{Notes}

The authors declare no competing financial interest.

\section{ACKNOWLEDGMENTS}

We thank Shell Global Solutions International B.V., the University of Oxford, and the EPSRC for financial support of this research (Industrial CASE studentship O.P.E.T.; EP/ M024210 to A.S.W.). The University of Oxford is also acknowledged for access to Chemical Crystallography facilities.

\section{REFERENCES}

(1) (a) Daeneke, T.; Khoshmanesh, K.; Mahmood, N.; de Castro, I. A.; Esrafilzadeh, D.; Barrow, S. J.; Dickey, M. D.; Kalantar-zadeh, K. Liquid metals: fundamentals and applications in chemistry. Chem. Soc. Rev. 2018, 47, 4073-4111. (b) Bo, G.; Ren, L.; Xu, X.; Du, Y.; Dou, S. Recent progress on liquid metals and their applications. Adv. Phys.: $X$ 2018, 3, 1446359.

(2) Upham, D. C.; Agarwal, V.; Khechfe, A.; Snodgrass, Z. R.; Gordon, M. J.; Metiu, H.; McFarland, E. W. Catalytic molten metals for the direct conversion of methane to hydrogen and separable carbon. Science 2017, 358, 917-921.

(3) Taccardi, N.; Grabau, M.; Debuschewitz, J.; Distaso, M.; Brandl, M.; Hock, R.; Maier, F.; Papp, C.; Erhard, J.; Neiss, C.; Peukert, W.; Görling, A.; Steinrück, H.-P.; Wasserscheid, P. Gallium-rich Pd-Ga phases as supported liquid metal catalysts. Nat. Chem. 2017, 9, 862867.

(4) Palmer, C.; Tarazkar, M.; Kristoffersen, H. H.; Gelinas, J.; Gordon, M. J.; McFarland, E. W.; Metiu, H. Methane Pyrolysis with a Molten $\mathrm{Cu}-\mathrm{Bi}$ Alloy Catalyst. ACS Catal. 2019, 9, 8337-8345.

(5) Palmer, C.; Upham, D. C.; Smart, S.; Gordon, M. J.; Metiu, H.; McFarland, E. W. Dry reforming of methane catalysed by molten metal alloys. Nat. Catal. 2020, 3, 83-89.

(6) Esrafilzadeh, D.; Zavabeti, A.; Jalili, R.; Atkin, P.; Choi, J.; Carey, B. J.; Brkljača, R.; O’Mullane, A. P.; Dickey, M. D.; Officer, D. L.; MacFarlane, D. R.; Daeneke, T.; Kalantar-Zadeh, K. Room temperature $\mathrm{CO}_{2}$ reduction to solid carbon species on liquid metals featuring atomically thin ceria interfaces. Nat. Commun. 2019, 10, 865-867.

(7) Schnepf, A. $\left[\mathrm{Ge}_{9}\left\{\mathrm{Si}\left(\mathrm{SiMe}_{3}\right)_{3}\right\}_{3}\right]^{-}$: A Soluble Polyhedral $\mathrm{Ge}_{9}$ Cluster Stabilized by Only Three Silyl Ligands. Angew. Chem., Int. Ed. 2003, 42, 2624-2625.

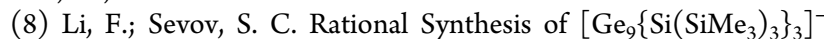
from Its Parent Zintl Ion $\mathrm{Ge}_{9}{ }^{4-}$. Inorg. Chem. 2012, 51, 2706-2708.

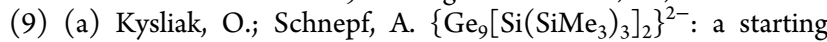
point for mixed substituted metalloid germanium clusters. Dalton Trans 2016, 45, 2404-2408. (b) Kysliak, O.; Schrenk, C.; Schnepf, A. $\left\{\left[\mathrm{Si}\left(\mathrm{SiMe}_{3}\right)_{3}\right]_{2} \mathrm{Ge}_{9}-\mathrm{SiMe}_{2}-\left(\mathrm{C}_{6} \mathrm{H}_{4}\right)-\mathrm{SiMe}_{2}-\mathrm{Ge}_{9}\left[\mathrm{Si}\left(\mathrm{SiMe}_{3}\right)_{3}\right]_{2} \mathrm{~K}\right\}^{-}:$The Connection of Metalloid Clusters via an Organic Linker. Inorg. Chem. 2017, 56, 9693-9697. (c) Kysliak, O.; Kunz, T.; Schnepf, A. Metalloid $\mathrm{Ge}_{9} \mathrm{R}_{3}{ }^{-}$Clusters with Various Silyl Substituents: From Shielded to Open Cluster Cores. Eur. J. Inorg. Chem. 2017, 2017, 805-810. (d) Mayer, K.; Schiegerl, L. J.; Kratky, T.; Günther, S.; Fässler, T. F. Targeted attachment of functional groups at $\mathrm{Ge}_{9}$ clusters via silylation reactions. Chem. Commun. 2017, 53, 11798-11801. (e) Geitner, F. S.; Wallach, C.; Fässler, T. F. On the Variable 
Reactivity of Phosphine-Functionalized $\left[\mathrm{Ge}_{9}\right.$ ] Clusters: Zintl ClusterSubstituted Phosphines or Phosphine-Substituted Zintl Clusters. Chem. - Eur. J. 2018, 24, 4103-4110.

(10) Geitner, F. S.; Klein, W.; Storcheva, O.; Tilley, T. D.; Fässler, T. F. Early-Transition-Metal Complexes of Functionalized Nonagermanide Clusters: Synthesis and Characterization of $\left[\mathrm{Cp}_{2}(\mathrm{MeCN}) \mathrm{Ti}\left(\eta^{1}\right.\right.$ $\left.\left.\mathrm{Ge}_{9}\left\{\mathrm{Si}(\mathrm{TMS})_{3}\right\}_{3}\right)\right]$ and $\mathrm{K}_{3}\left[\mathrm{Cp}_{2} \mathrm{Ti}\left(\eta^{1}-\mathrm{Ge}_{9}\left\{\mathrm{Si}(\mathrm{TMS})_{3}\right\}_{2}\right)_{2}\right]$. Inorg. Chem. 2019, 58, 13293-13298.

(11) (a) Schenk, C.; Schnepf, A. $\left\{\mathrm{Ge}_{9} \mathrm{R}_{3} \mathrm{Cr}(\mathrm{CO})_{5}\right\}^{-}$and $\left\{\mathrm{Ge}_{9} \mathrm{R}_{3} \mathrm{Cr}-\right.$ $\left.(\mathrm{CO})_{3}\right\}^{-}$: a metalloid cluster $\left(\mathrm{Ge}_{9} \mathrm{R}_{3}^{-}\right)$as a flexible ligand in coordination chemistry $\left[\mathrm{R}=\mathrm{Si}\left(\mathrm{SiMe}_{3}\right)_{3}\right]$. Chem. Commun. 2009, 3208-3210. (b) Henke, F.; Schenk, C.; Schnepf, A. [Si$\left.\left(\mathrm{SiMe}_{3}\right)_{3}\right]_{3} \mathrm{Ge}_{9} \mathrm{M}(\mathrm{CO})_{3}{ }^{-}(\mathrm{M}=\mathrm{Cr}, \mathrm{Mo}, \mathrm{W})$ : Coordination Chemistry with Metalloid Clusters. Dalton Trans 2011, 40, 6704-6710. (c) Kysliak, O.; Schrenk, C.; Schnepf, A. Reactivity of $\left[\mathrm{Ge}_{9}\{\mathrm{Si}-\right.$ $\left.\left.\left(\mathrm{SiMe}_{3}\right)_{3}\right\}_{3}\right]^{-}$Towards Transition-Metal $\mathrm{M}^{2+}$ Cations: Coordination and Redox Chemistry. Chem. - Eur. J. 2016, 22, 18787-18793. (d) Michenfelder, N. C.; Gienger, C.; Schnepf, A.; Unterreiner, A. N. The influence of the $\mathrm{FeCp}(\mathrm{CO})_{2}{ }^{+}$moiety on the dynamics of the metalloid $\left.\left[\mathrm{Ge}_{9}\left(\mathrm{Si}_{(\mathrm{SiMe}}\right)_{3}\right)_{3}\right]^{-}$cluster in thf: synthesis and characterization by time-resolved absorption spectroscopy. Dalton Trans 2019, $48,15577-15582$.

(12) (a) Schenk, C.; Schnepf, A. $\left[\mathrm{AuGe}_{18}\left\{\mathrm{Si}\left(\mathrm{SiMe}_{3}\right)_{3}\right\}_{6}\right]^{-}$: A Soluble $\mathrm{Au}-\mathrm{Ge}$ Cluster on the Way to a Molecular Cable? Angew. Chem., Int. Ed. 2007, 46, 5314-5316. (b) Schenk, C.; Henke, F.; SantisoQuiñones, G.; Krossing, I.; Schnepf, A. [ $\left.\mathrm{Si}\left(\mathrm{SiMe}_{3}\right)_{3}\right]_{6} \mathrm{Ge}_{18} \mathrm{M}(\mathrm{M}=\mathrm{Cu}$, $\mathrm{Ag}, \mathrm{Au}$ ): metalloid cluster compounds as unusual building blocks for a supramolecular chemistry. Dalton Trans 2008, 4436-4441.

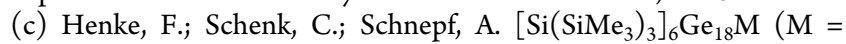
$\mathrm{Zn}, \mathrm{Cd}, \mathrm{Hg}$ ): neutral metalloid cluster compounds of germanium as highly soluble building blocks for supramolecular chemistry. Dalton Trans 2009, 9141-9145. (d) Li, F.; Muñoz-Castro, A.; Sevov, S. C. $\left[\mathrm{Ge}_{9}\left\{\mathrm{Si}\left(\mathrm{SiMe}_{3}\right)_{3}\right\}_{3}\left\{\mathrm{SnPh}_{3}\right\}\right]$ : a tetrasubstituted and neutral deltahedral nine-atom cluster. Angew. Chem., Int. Ed. 2012, 51, 8581-8584. (e) Li, F.; Sevov, S. C. Coordination of Tri-Substituted NonaGermanium Clusters to $\mathrm{Cu}(\mathrm{I})$ and $\mathrm{Pd}(0)$. Inorg. Chem. 2015, 54, 8121-8125. (f) Kysliak, O.; Schrenk, C.; Schnepf, A. $\left\{\mathrm{Ge}_{9}[\mathrm{Si}-\right.$ $\left.\left.\left(\mathrm{SiMe}_{3}\right)_{2}\left(\mathrm{SiPh}_{3}\right)\right]_{3}\right\}^{-}$: Ligand Modification in Metalloid Germanium Cluster Chemistry. Inorg. Chem. 2015, 54, 7083-7088. (g) Li, F.; Muñoz-Castro, A.; Sevov, S. C. $\left[\left(\mathrm{Me}_{3} \mathrm{Si}\right) \mathrm{Si}\right]_{3} \mathrm{EtGe}_{9} \quad \mathrm{Pd}\left(\mathrm{PPh}_{3}\right)$, a Pentafunctionalized Deltahedral Zintl Cluster: Synthesis, Structure, and Solution Dynamics. Angew. Chem., Int. Ed. 2016, 55, 8630-8633. (h) Geitner, F. S.; Fässler, T. F. Introducing Tetrel Zintl Ions to NHeterocyclic Carbenes - Synthesis of Coinage Metal NHC Complexes of $\left[\mathrm{Ge}_{9}\left\{\mathrm{Si}\left(\mathrm{SiMe}_{3}\right)_{3}\right\}_{3}\right]^{-}$. Eur. J. Inorg. Chem. 2016, 2016, 2688-2691. (i) Mayer, K.; Schiegerl, L. J.; Fässler, T. F. On the Reactivity of Silylated $\mathrm{Ge}_{9}$ Clusters: Synthesis and Characterization of

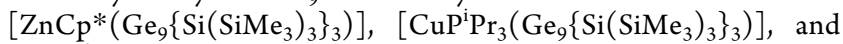
$\left[\left(\mathrm{CuP}^{\mathrm{i}} \mathrm{Pr}_{3}\right)_{4}\left\{\mathrm{Ge}_{9}\left(\mathrm{SiPh}_{3}\right)_{2}\right\}_{2}\right]$. Chem. - Eur. J. 2016, 22, 1879418800. (j) Geitner, F. S.; Dums, J. V.; Fässler, T. F. Derivatization of Phosphine Ligands with Bulky Deltahedral Zintl Clusters-Synthesis of Charge Neutral Zwitterionic Tetrel Cluster Compounds $\left[\left(\mathrm{Ge}_{9}\{\mathrm{Si}-\right.\right.$ $\left.\left.\left.(\mathrm{TMS})_{3}\right\}_{2}\right)^{\mathrm{t}} \mathrm{Bu}_{2} \mathrm{P}\right] \mathrm{M}\left(\mathrm{NHC} \mathrm{C}^{\mathrm{Dipp}}\right)$ (M: Cu, Ag, Au). J. Am. Chem. Soc. 2017, 139, 11933-11940. (k) Geitner, F. S.; Giebel, M. A.; Pöthig, A.; Fässler, T. F. N-Heterocyclic Carbene Coinage Metal Complexes of the Germanium-Rich Metalloid Clusters $\left[\mathrm{Ge}_{9} \mathrm{R}_{3}\right]^{-}$and $\left[\mathrm{Ge}_{9} \mathrm{R}_{2}\right]^{2-}$ with $\mathrm{R}=\mathrm{Si}\left({ }^{\mathrm{i}} \mathrm{Pr}\right)_{3}$ and $\mathrm{R}^{\mathrm{I}}=\mathrm{Si}(\mathrm{TMS})_{3}$. Molecules 2017, 22, 1204 . (1) Kysliak, O.; Nguyen, D. D.; Clayborne, A. Z.; Schnepf, A. $\left[\mathrm{PtZn}_{2} \mathrm{Ge}_{18}(\mathrm{Hyp})_{8}\right]\left(\mathrm{Hyp}=\mathrm{Si}\left(\mathrm{SiMe}_{3}\right)_{3}\right)$ : A Neutral Polynuclear Chain Compound with $\mathrm{Ge}_{9}(\mathrm{Hyp})_{3}$ Units. Inorg. Chem. 2018, 57, 12603-12609. (m) Frischhut, S.; Kaiser, F.; Klein, W.; Drees, M.; Kühn, F. E.; Fässler, T. F. Capping nido-Nonagermanide Clusters with $\mathrm{M}-\mathrm{PPh}_{3}$ and Dynamics in Solution: Synthesis and Structure of closo$\left[\left(\mathrm{Me}_{3} \mathrm{Si}\right)_{3} \mathrm{Si}\right]_{3} \mathrm{Et}\left[\mathrm{Ge}_{9} \mathrm{M}\right]\left(\mathrm{PPh}_{3}\right)(\mathrm{M}=\mathrm{Ni}, \mathrm{Pt})$. Organometallics 2018, 37, 4560-4567. (n) Schiegerl, L. J.; Melaimi, M.; Tolentino, D. R.; Klein, W.; Bertrand, G.; Fässler, T. F. Silylated $\mathrm{Ge}_{9}$ Clusters as New Ligands for Cyclic (Alkyl)amino and Mesoionic Carbene Copper Complexes. Inorg. Chem. 2019, 58, 3256-3264. (o) Kysliak, O.; Schnepf, A. $\left[\mathrm{Ge}_{9}\left\{\mathrm{Si}_{(}\left(\mathrm{SiMe}_{3}\right)_{3}\right\}_{2}\left\{\mathrm{Ge}\left(\mathrm{SiMe}_{3}\right)_{3}\right\}\right]^{-}$: The Mixed Sub- stituted Metalloid Germanium Cluster and the Intermetalloid Cluster $\left[\mathrm{ZnGe}_{18}\left\{\mathrm{Si}\left(\mathrm{SiMe}_{3}\right)_{3}\right\}_{4}\left\{\mathrm{Ge}\left(\mathrm{SiMe}_{3}\right)_{3}\right\}_{2}\right]$. Z. Anorg. Allg. Chem. 2019, 645, 335-339.

(13) Zintl clusters have previously been shown to be involved in stoichiometric bond activation reactions involving solvents or reagent ligands. For example, see: (a) Weinert, B.; Eulenstein, A. R.; Ababei, R.; Dehnen, S. Formation of $\left[\mathrm{Bi}_{11}\right]^{3-}$, a Homoatomic, Polycyclic Bismuth Polyanion, by Pyridine-Assisted Decomposition of $\left[\mathrm{GaBi}_{3}\right]^{2-}$. Angew. Chem., Int. Ed. 2014, 53, 4704-4708. (b) Weinert, B.; Müller, F.; Harms, K.; Clérac, R.; Dehnen, S. Origin and Location of Electrons and Protons during the Formation of Intermetalloid Clusters $\left[\mathrm{Sm} @ \mathrm{Ga}_{3-x} \mathrm{H}_{3-2 x} \mathrm{Bi}_{10+x}\right]^{3-}(x=0,1)$. Angew. Chem., Int. Ed. 2014, 53, 11979-11983.

(14) For a recent review, see: Wilson, R. J.; Weinert, B.; Dehnen, S. Recent developments in Zintl cluster chemistry. Dalton Trans 2018, 47, 14861-14869.

(15) (a) Eichhorn, B. W.; Haushalter, R. C.; Pennington, W. T. Synthesis and structure of closo- $\mathrm{Sn}_{9} \mathrm{Cr}(\mathrm{CO})_{3}{ }^{4-}$ : The first member in a new class of polyhedral clusters. J. Am. Chem. Soc. 1988, 110, 87048706. (b) Eichhorn, B. W.; Haushalter, R. C. Closo- $\left[\mathrm{CrPb}_{9}(\mathrm{CO})_{3}\right]^{4-}$ : a 100 year history of the nonaplumbide tetra-anion. J. Chem. Soc., Chem. Commun. 1990, 937-938. (c) Kesanli, B.; Fettinger, J.; Eichhorn, B. The closo- $\left[\mathrm{Sn}_{9} \mathrm{M}(\mathrm{CO})_{3}\right]^{4-}$ Zintl Ion Clusters where $\mathrm{M}=$ $\mathrm{Cr}, \mathrm{Mo}, \mathrm{W}$ : Two Structural Isomers and Their Dynamic Behavior. Chem. - Eur. J. 2001, 7, 5277-5285. (d) Campbell, J.; Mercier, H. P. A.; Franke, H.; Santry, D. P.; Dixon, D. A.; Schrobilgen, G. J. Syntheses, Crystal Structures, and Density Functional Theory Calculations of the closo- $\left[1-\mathrm{M}(\mathrm{CO})_{3}\left(\eta^{4}-\mathrm{E}_{9}\right)\right]^{--}(\mathrm{E}=\mathrm{Sn}, \mathrm{Pb} ; \mathrm{M}=$ $\mathrm{Mo}, \mathrm{W})$ Cluster Anions and Solution NMR Spectroscopic Characterization of $\left[1-\mathrm{M}(\mathrm{CO})_{3}\left(\eta^{4}-\mathrm{Sn}_{9}\right)\right]^{4-}(\mathrm{M}=\mathrm{Cr}, \mathrm{Mo}, \mathrm{W})$. Inorg. Chem. 2002, 41, 86-107.

(16) (a) Wang, J.-Q.; Stegmaier, S.; Wahl, B.; Fässler, T. F. Step-byStep Synthesis of the Endohedral Stannaspherene $\left[\mathrm{Ir} @ \mathrm{Sn}_{12}\right]^{3-}$ via the Capped Cluster Anion $\left[\mathrm{Sn}_{9} \operatorname{Ir}(\mathrm{cod})\right]^{3-}$. Chem. - Eur. J. 2010, 16, 1793-1798. (b) Downing, D. O.; Zavalij, P.; Eichhorn, B. W. The closo- $\left[\mathrm{Sn}_{9} \operatorname{Ir}(\operatorname{cod})\right]^{3-}$ and $\left[\mathrm{Pb}_{9} \operatorname{Ir}(\operatorname{cod})\right]^{3-}$ Zintl Ions: Isostructural $\mathrm{Ir}^{\mathrm{I}}$ Derivatives of the nido- $\mathrm{E}_{9}{ }^{4-}$ Anions $(\mathrm{E}=\mathrm{Sn}, \mathrm{Pb})$. Eur. J. Inorg. Chem. 2010, 2010, 890-894.

(17) Based on 1900 entries of complexes featuring a $\mathrm{Rh}(\mathrm{COD})$ moiety in the Cambridge Structural Database, version 5.41 (November 2019).

(18) Wender, P. A.; Williams, T. J. [(arene) Rh(cod) $]^{+}$Complexes as Catalysts for $[5+2]$ Cycloaddition Reactions. Angew. Chem., Int. Ed. 2002, 41, 4550-4553.

(19) Berkeley, E. R.; Perez-Gavilan, A.; Carroll, P. J.; Sneddon, L. G. Syntheses, Structural Characterizations, and Reactivity Studies of Half-Sandwich Cobalt, Rhodium, and Iridium Metallatricarbadecaboranyl Complexes. Organometallics 2015, 34, 1396-1407.

(20) Fischer, C.; Thede, R.; Drexler, H.-J.; König, A.; Baumann, W.; Heller, D. Investigations into the Formation and Stability of Cationic Rhodium Diphosphane $\eta^{6}$-Arene Complexes. Chem. - Eur. J. 2012, 18, 11920-11928.

(21) Based on 80 entries of complexes featuring a $\mathrm{Rh}$ (dppe) moiety in the Cambridge Structural Database, version 5.41 (November 2019).

(22) Meißner, A.; Alberico, E.; Drexler, H.-J.; Baumann, W.; Heller, D. Rhodium diphosphine complexes: a case study for catalyst activation and deactivation. Catal. Sci. Technol. 2014, 4, 3409-3425.

(23) The use of Zintl clusters as precursors to heterogeneous catalysts was recently reported. See: Wang, Y.; Zhang, C.; Wang, X.; Guo, J.; Sun, Z.-M.; Zhang, H. Site-Selective $\mathrm{CO}_{2}$ Reduction over Highly Dispersed $\mathrm{Ru}-\mathrm{SnO}_{\mathrm{x}}$ Sites Derived from a $\left[\mathrm{Ru} @ \mathrm{Sn}_{9}\right]^{6-}$ Zintl Cluster. ACS Catal. 2020, 10, 7808-7819.

(24) Related siliconoid clusters have recently been shown to be active in alkene isomerization. See: Poitiers, N. E.; Giarrana, L.; Huch, V.; Zimmer, M.; Scheschkewitz, D. Exohedral functionalization vs. core expansion of siliconoids with Group 9 metals: catalytic activity in alkene isomerization. Chem. Sci. 2020, 11, 7782-7788. 
(25) Luo, J.; Wu, Y.; Zijlstra, H. S.; Harrington, D. A.; McIndoe, J. S. Mass transfer and convection effects in small-scale catalytic hydrogenation. Catal. Sci. Technol. 2017, 7, 2609-2615.

(26) Widegren, J. A.; Finke, R. G. A review of the problem of distinguishing true homogeneous catalysis from soluble or other metal-particle heterogeneous catalysis under reducing conditions. $J$. Mol. Catal. A: Chem. 2003, 198, 317-341.

(27) Hoops, S.; Sahle, S.; Gauges, R.; Lee, C.; Pahle, J.; Simus, N.; Singhal, M.; Xu, L.; Mendes, P.; Kummer, U. COPASI: a COmplex PAthway SImulator. Bioinformatics 2006, 22, 3067-74. 